\title{
Modelling and Simulation of Vessel Alongside Replenishment Motion Response Based on Sea Conditions Analysis
}

\author{
Zhengnan $\mathrm{JI}^{1, \mathrm{a}}$, Limin TAO ${ }^{1}$ and Wei LV ${ }^{1}$ \\ ${ }^{1}$ Science and Technology on Integrated Logistics Support Laboratory, National University of Defense Technology, \\ 410073 Changsha, P.R. China
}

\begin{abstract}
Offshore accurate replenishment technology is a vital basement of conducting ocean research and deep ocean exploitation for every advanced country. However, It's necessary to compensate waving for ensuring the security and accuracy of offshore project due to the fact that wave makes vessel generate 6-DOF motions. This paper set offshore accurate supplying for vessels as the background, basing on Froude-Krylov assumption, to do research on 6-DOF motion responses of different sea conditions. This paper builds the vessel motion response formulas on the basis of the 3-dimensional potential theory and then resolve it by AQWA. The simulation results indicate the regularity of vessel motions, which can be considered as requirement indicators during designing AHC (Active Heaving Compensation) system.
\end{abstract}

\section{Introduction}

The vessel sailing in the blue ocean is not only an important platform for conducting ocean research for every institutes but also an elementary unit of every country's navy for executing the escort task [1]. Moreover, with the increasingly complexity and high-consuming during the offshore working, the lifting of target is becoming an essential project gradually.

Offshore replenishment refers to the process of vessel offering supplies (energy, oil etc.) to other vessels in the ocean [2], which is a significant way to achieve deep ocean sailing for vessels. Generally speaking, offshore replenishment can be divided into four styles according to the double vessels' relative positions, including horizontal replenishment, longitudinal replenishment, vertical replenishment and alongside replenishment. Their specifications have been shown in the Table 1 [25].

Table 1. The specifications of four kinds of replenishment.

\begin{tabular}{|c|c|c|c|c|c|}
\hline Types & $\begin{array}{c}\text { Theorical } \\
\text { Accuracy }\end{array}$ & $\begin{array}{c}\text { Loads per } \\
\text { Time }\end{array}$ & $\begin{array}{c}\text { Theorical } \\
\text { Security }\end{array}$ & $\begin{array}{c}\text { Financial } \\
\text { Cost }\end{array}$ & $\begin{array}{c}\text { Technology } \\
\text { Maturity }\end{array}$ \\
\hline Horizontal & Fair & Good & Fair & Lowest & Good \\
\hline Longitudinal & Poor & Fair & Poor & Low & Fair \\
\hline Vertical & Good & Poor & Good & High & Fair \\
\hline Alongside & Very good & Very good & Good & Low & Poor \\
\hline
\end{tabular}

\footnotetext{
${ }^{a}$ Corresponding author: banzhu365@163.com
} 
The vessel will generate 6-DOF motions under the restoring force and inertia force of the seawater due to the influence of wind force [3]. There are translation vectors paralleled to $\mathrm{X}, \mathrm{Y}, \mathrm{Z}$ axis (surging $x$, swaying $y$, heaving $z$ ) and rotation vectors using $\mathrm{X}, \mathrm{Y}, \mathrm{Z}$ axis as pivot respectively (rolling $\varphi$, pitching $\theta$ and yawing $\psi$ ). In order to compensate for the wave motions in the alongside replenishment, AHC technology is always adopted to ensure the security of hoisting. It is necessary to gain the knowledge of vessels time response and its amplitude for acquiring the range of detection and control in the development of AHC mechanism. Therefore, the project concerning alongside replenishment is vital to comprehensive analysis of double vessel relative motions in the sea.

So far, a variety of institutes has conducted some research in different fields. Yan built the differential formulas of vessel motions and solved it with Runge-Kutta algorithm [4]. Shi conducted the frequency domain's research based on the three-dimensional potential theory and then built the simulation model of alongside replenishment [5]. Lu designed the infinitely variable speeds mechanism to conduct simulative experiment of alongside replenishment for missile supplying between two vessels [6]. Ebbesen studied on the FPSO's structure whose anchor lines and production risers are linked to the floater and then simulated the vessel motions based on SIMO and RIFLEX [7].

\section{Geometry Modelling and Relative Theory}

The vessel models are derived from comprehensive replenishment vessel and warship served in the navy. According to the actual condition of replenishment in the sea, the model scheme has considered mooring and protection in the simulation process.

\subsection{Vessel Models Selection}

Take secrecy into consideration, the paper adopts approximate data to do research. We adopt nonuniform scaling methodology to model vessel. Details about modeling are shown in the Table 2 .

Table 2. The parameters of two vessels.

\begin{tabular}{|c|c|c|c|c|c|c|}
\hline Type & Length & Length Ratio & Beam & Beam Ratio & $\begin{array}{c}\text { Gravity } \\
\text { Height }\end{array}$ & $\begin{array}{c}\text { Water } \\
\text { Line }\end{array}$ \\
\hline $\mathrm{A}$ & $171.4 \mathrm{~m}$ & 0.840 & $24.6 \mathrm{~m}$ & 0.683 & $3.0 \mathrm{~m}$ & $6.0 \mathrm{~m}$ \\
\hline $\mathrm{B}$ & $156.8 \mathrm{~m}$ & 0.768 & $18.9 \mathrm{~m}$ & 0.525 & $2.0 \mathrm{~m}$ & $4.0 \mathrm{~m}$ \\
\hline
\end{tabular}

The paper designs a prototype vessel whose scale is $204 \mathrm{~m} \times 36 \mathrm{~m} \times 16 \mathrm{~m}$. Two vessels were generated by scaling the vessel and their center of gravity are both located in the $0.5 \mathrm{~m}$ along the $\mathrm{Z}$ axis positive direction. Then we can acquire rotation rigidness value from these three empirical equations.

$$
K_{x x}=0.34 \times \text { Beam }, K_{y y}=0.25 \times \text { Length }, K_{z z}=0.26 \times \text { Length }
$$

In order to describe the wave, vessel motion and flow field, we introduce these three coordinates showed in the Figure 1. The 6-DOF motion of single vessel are showed in the Figure 1 as well.
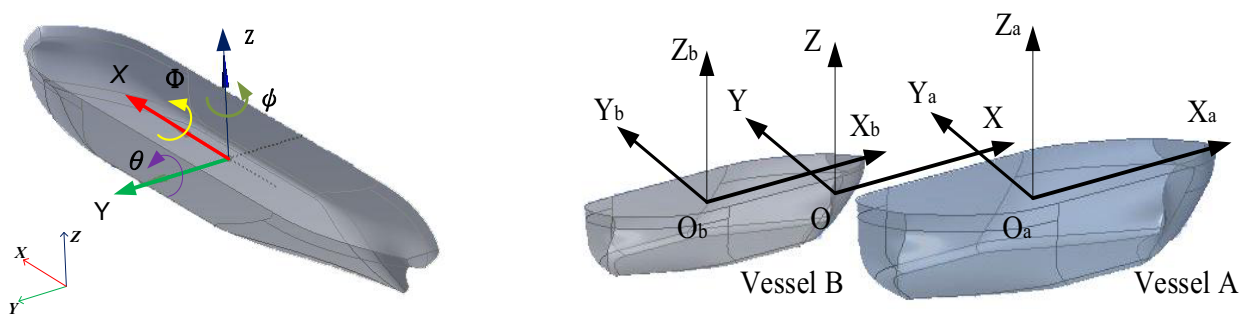

Figure 1. Coordinates setting.

In the Figure 1, there are world fixed coordinates $\mathrm{O}-\mathrm{XYZ}(\mathrm{O}-\mathrm{XY}$ plane is located in the undisturbed plane. $\mathrm{O}-\mathrm{Z}$ axis is vertical to upright.) and vessel motion coordinates $\mathrm{O}_{\mathrm{i}}-\mathrm{X}_{\mathrm{i}} \mathrm{Y}_{\mathrm{i}} \mathrm{Z}_{\mathrm{i}}(\mathrm{i}=\mathrm{a}, \mathrm{b})$ 
fixed in the vessel (coordinates $\mathrm{O}_{\mathrm{i}}$ is selected in the gravity center. $\mathrm{X}_{\mathrm{i}}$ axis is paralleled to vessel baseline pointing at vessel bow. $Z_{\mathrm{i}}$ axis is vertical to vessel waterline.). The second coordinates will not sway with the motion of the vessel and its $Z$ axis will keep vertical to upright forever. Wave angle is represented by $m$, Wave is called top wave when $m=180^{\circ}$ and wave is called starboard wave when $m=90^{\circ}$.

\subsection{Three-Dimensional Potential Theory}

Potential theory is the prevalent solution to calculate the wave force of structural surface which sets velocity potential, Laplace formula and four boundary conditions. The velocity potential can be uniquely determined according to Laplace formula and the boundary conditions. Then, the force of the wet surface can be calculated by Bernoulli Formula [8]. There is some difference between single vessel and double vessel working in the sea. It is that the velocity potential can be divided into wave incident potential $\Phi_{I}$, self-diffraction potential, adjacent diffraction $\Phi_{D}$ and radiation potential $\Phi_{R}$ [5].

$$
\Phi=\Phi_{I}+\Phi_{D}+\Phi_{R}=\operatorname{Re}\left\{\left[\phi_{I}(\mathrm{x}, \mathrm{y}, \mathrm{z})+\phi_{D}(\mathrm{x}, \mathrm{y}, \mathrm{z})+\phi_{R}(\mathrm{x}, \mathrm{y}, \mathrm{z})\right] \mathrm{e}^{-i \omega t}\right\}
$$

It should be noted that there is an assupmtion (Small Amplitude Wave Theory) that the fluid is ideal for incompressible fluid, non-sticky, without spin, and infinite depth.

\section{Loads of Alongside Replenishment}

Sea loads refer to the loads derived from environmental impact indirectly or immediately, including all of external forces (mooring force, motion inertial force and sloshing force etc.) [9]. In order to describe the model clearly, the paper considered and calculated the wind, wave, current sea loads, mooring loads and protection loads based on Froude-Krylov assumption, as shown in the Figure 2.

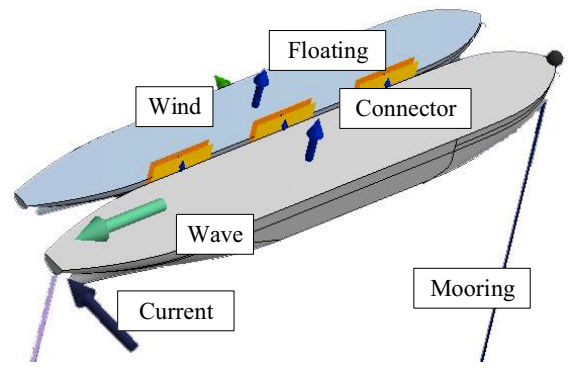

Figure 2. The sketch charts of sea loads.

Meanwhile, the paper ignores unimportant factors like deck loads and vibration derived from Karman Vortex. The 6-DOF motion formula of the structure can be listed based on Newton's second law.

$$
\sum_{k=1}^{6} M_{j k} \ddot{x_{k}}=F_{H S}+F_{E X}+F_{R}+F_{M}
$$

\subsection{Environmental Wind Load}

As for the infinite working platform, the minimum wind velocity should be $51.5 \mathrm{~m} / \mathrm{s}$ and $36.0 \mathrm{~m} / \mathrm{s}$ in different working mode respectively [10]. Environmental wind load can be calculated by the formula according to the selected wind velocity.

$$
P=0.613 \times 10^{-3} C_{h} C_{S} S V^{2}
$$

Among that, $P$ is the wind force. $S$ is the positive projection area. $C_{h}$ is height coefficient. $C_{s}$ is shape coefficient. $V$ is designed wind velocity. The $C_{h}$ and $C_{s}$ should be selected by height and shape. 


\subsection{Wave Effect Load}

Wave load $p$ is able to be divided into three parts corresponding to incident potential, diffraction potential and radiation potential. The first part is the force dominating the distorted force. The second part is diffraction force. The third part is liquid impact inverse force induced by radiation potential. The detailed equation is shown in the Formula 5. $\rho$ is density of seawater and $z$ is depth of it.

$$
p=-\rho g z-\rho \frac{\partial \Phi}{\partial t}=-\rho g z-\rho\left(\frac{\partial \Phi_{I}}{\partial t}+\frac{\partial \Phi_{D}}{\partial t}+\frac{\partial \Phi_{R}}{\partial t}\right)
$$

Finally, the wave force of the structure $F$ and $M$ can be acquired with these following Formulas 6 .

$$
F=\iint_{S}-p n d s \quad M=\iint_{S}-p(\mathrm{r} \times n) d s
$$

\subsection{Current Effect Load}

The designed flow velocity should be selected to the maximum velocity, which includes tidal current, velocity storm, surge wind velocity. In addition, the vertical flow velocity distribution should be considered. The flow effect load can be calculated by Formula 7 if we only consider current.

$$
F=\frac{1}{2} C_{D} \rho_{W} V^{2} A
$$

Among that, $C_{d}$ is drag force coefficient. $P_{w}$ is seawater density. $V$ is designed current velocity. $A$ is the projected area of the member on the plane perpendicular to the flow velocity $v_{c}$.

$$
V_{c}=\frac{1}{T} \int_{0}^{T}\left(v_{c}\right)^{2} d s
$$

Designed current velocity $V_{c}$ can be calculated by Formula 8 when we apply diffraction theory.

\subsection{Mooring and Protection Mechanism}

It is difficult to control the vessels relative motions in the high level sea conditions. Thus we have to let the vessel moored to the bottom of the ocean. Meanwhile, for the sake of security, replenishment vessel and warship are supposed to be connected by cables and fenders [5].

The cables between two riggings should be flexible and its length is supposed to be suitable. It will generate trailing reaction if the riggings are too long. However, the flexible riggings will become a rigid body if the riggings are too short. Moreover, it is necessary to design protections mechanism (fenders) between two vessels because the vessels will generate clash in the process of replenishment. The fender is floating structure which cannot only keep safety but also decrease financial cost.

\section{Motion Response Simulation Based on AQWA}

With the development of finite element theory, more and more institutes try to apply the AQWA to solve water hydrodynamic and hydrostatic problem [11]. The paper adopts the AQWA to build the analysis model in the simulative condition and explains the hydrodynamic problem. The red curves refer to replenishment vessel and blue curves refer to the warship in all of the following figures.

\subsection{RAOs Analysis of Still Water}

AQWA-LINE module can calculate the wave force derived from diffraction and radiation around arbitrary shape structure. This module will use typical Green Function to resolve the wave force of floating structure. Each element in the gridding will be given a simulating source.

As can be illustrated in the Figure 3, there is a peak frequency in every DOF motion in the simulative curves except for the $\mathrm{Y}$ axis translation. The reason is that the fenders and cables can offer the comfortable restraint. The motions heaving $z$, rolling $\varphi$ and pitching $\theta$ are important factors in the 
process of hydrostatic analysis. They are about $0.81 \mathrm{rad} / \mathrm{s}, 0.57 \mathrm{rad} / \mathrm{s}$ and $0.82 \mathrm{rad} / \mathrm{s}$ for $z, \varphi$ and $\theta$ respectively. The phenomenon indicates that the replenishment process is able to avoid the resonance frequency easily. And it can draw a conclusion that the model can be applied to do research in terms of hydrodynamic analysis in the next section. By the way, the resonance frequency can be adjusted by the rigidness of the fender in the actual application.
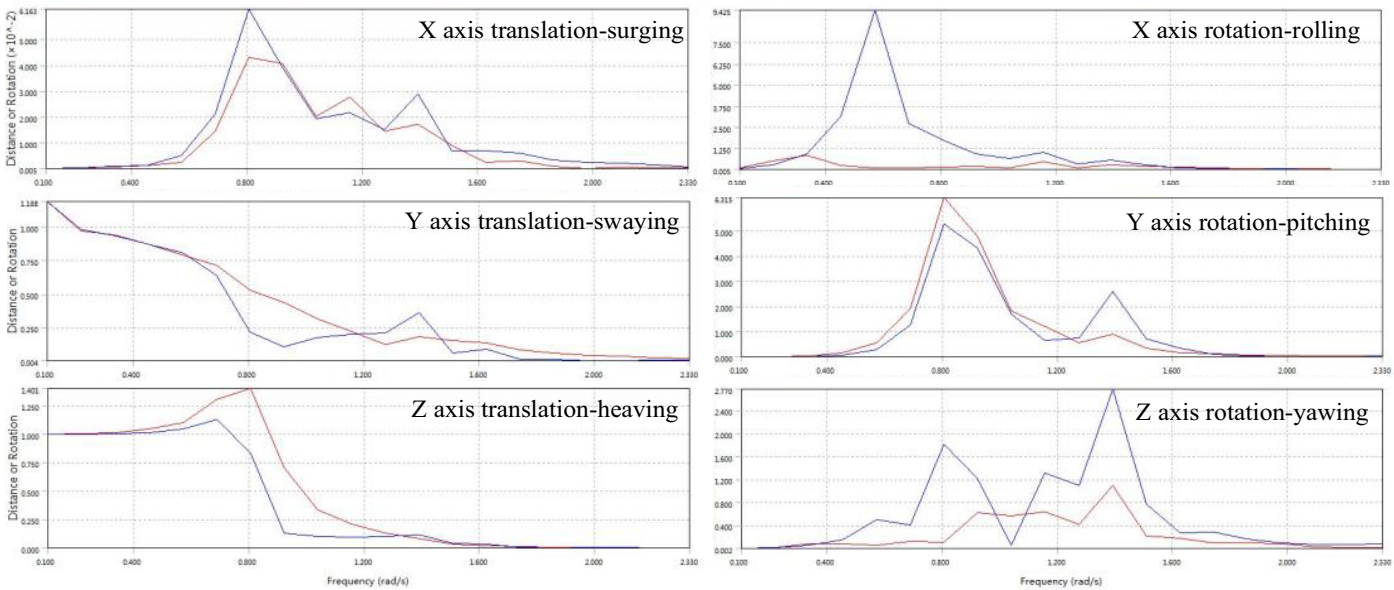

Figure 3. RAOs curves in the still water analysis.

\subsection{Time Response Simulation}

The AQWA-DRIFT module can be applied to calculate the time response and the corresponding loads in the total process under the random wave condition.
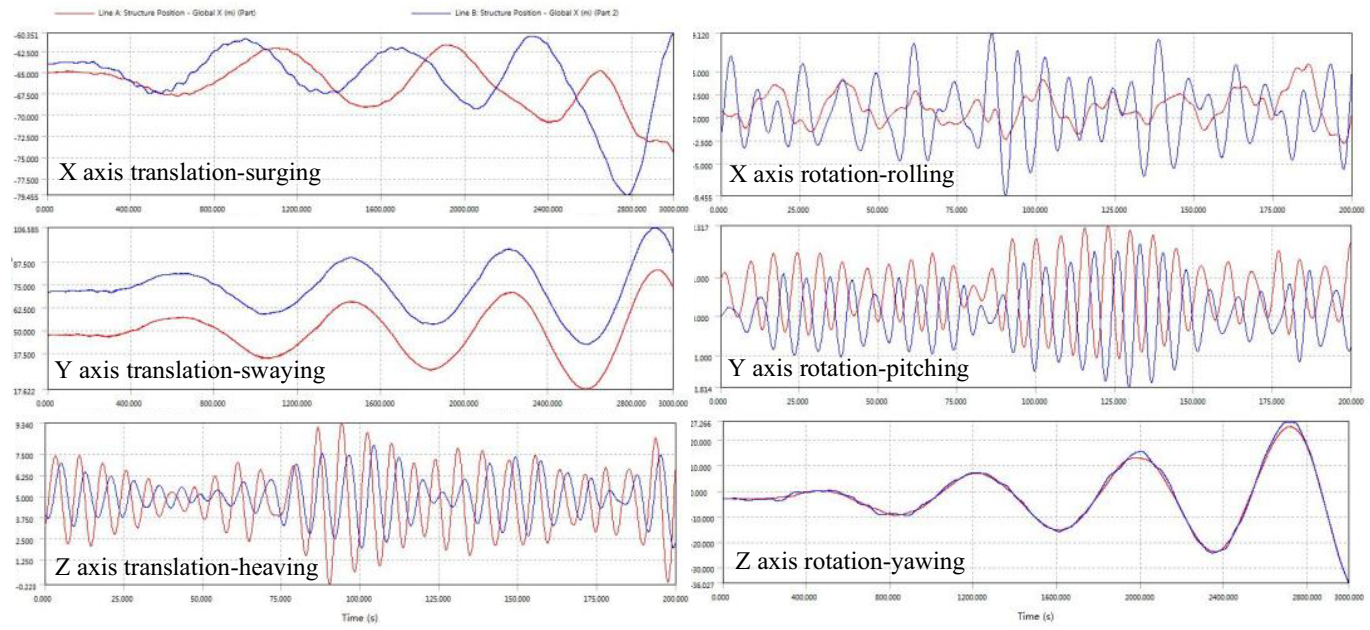

Figure 4. Time response curves of double vessel.

As can be illustrated in the Figure 4, surging $x$, swaying $y$, yawing $\psi$ are low frequency motions due to the existence of cables and fenders again. We are only interested in their amplitude maximum values. They are $4.413 \mathrm{~m}, 32.86 \mathrm{~m}$ and $30.5^{\circ}$ (absolute values of single vessel motion data) for $x, y$ and $\psi$ respectively. High frequency motion heaving $z$, rolling $\varphi$ and pitching $\theta$ are significant factors in the process of hydrostatic analysis. In order to display the result clearly, these three curve's horizontal axes have been shortened to 200 seconds so that we can acquire vessel motion response frequency values easily. They are about $1.8 \mathrm{~Hz}, 2.0 \mathrm{~Hz}$ and $2.1 \mathrm{~Hz}$ for $z, \varphi$ and $\theta$ respectively. 


\subsubsection{Comparison of Motion Response Varied from Different Wave Models.}

In the analysis of the Hydrodynamic response, the AQWA module has offered three kinds of irregular wave spectrum. They are JONSWAP wave, Pierson-Moskowitz wave and Gaussian wave. This section shows the comparison of the rolling in the 6-DOF motions under level 2 sea condition.

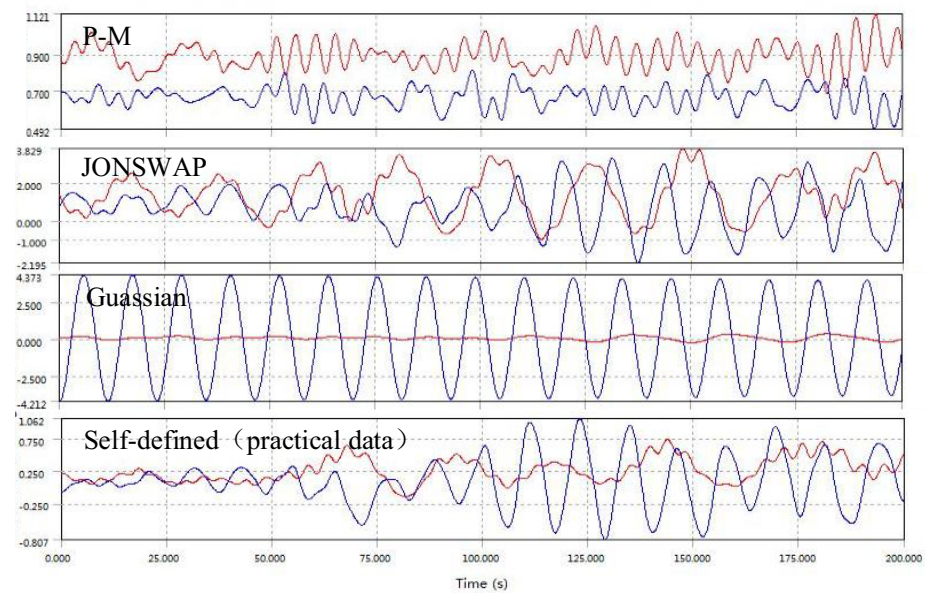

Figure 5. Comparison of motion response varied from different wave models (rolling).

As can be illustrated in the Figure 5, there is obviously much difference between four results based on different wave model. The rolling angle are about $1.121^{\circ}, 3.829^{\circ}, 4.373^{\circ}$ and $1.062^{\circ}$ for PiersonMoseowitz specturm, JONSWAP specturm, Gaussian specturm and self-defined spectrum. Obviously, the data from P-M specturm is closer to self-prepared data. P-M spectrum represents the observed quantity of growing waving that is special for ideal sea condition. Whereas, JONSWAP is more suitable and compatible in the actual application in terms of the waving's relative motion status.

\subsubsection{Comparison of Motion Response Varied from Different Sea Levels}

This section selects four sea levels from 2 to 5 to simulate the motion of two vessels in the sea. The parameter of simulation condition is ranged from $0.5978 \mathrm{~m}$ to $3.612 \mathrm{~m}$ in terms of significant average wave height. The angular frequency is ranged from $0.4973 \mathrm{~Hz}$ to $3.225 \mathrm{~Hz}[10]$.

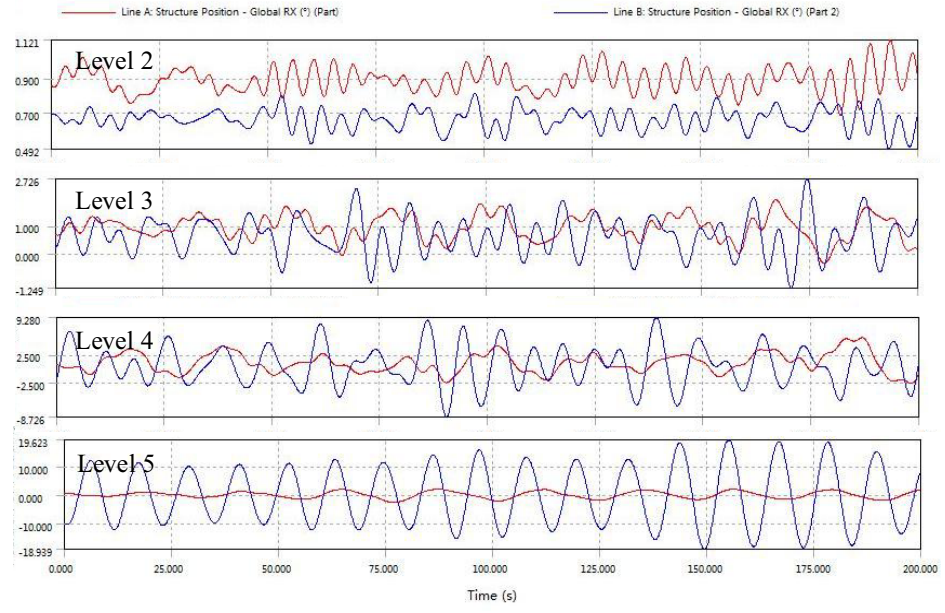

Figure 6. Comparison of motion response varied from different sea levels (rolling). 
As can be illustrated in the Figure 6, the motion frequency and phase position is various because of the difference of the time response amplitude under different sea condition levels. In the Figure 6, there are four levels from level 2 to level 5. The motion trails in level 2 is almost same for two vessels due to gentle sea condition. However, in level 3 and 4, the warship motions are more intensive. Specially, the motions of two vessels will become steady and regular in level 5. Detailed results about relative poses' maximum amplitude between two vessels have been settled in the Table 3.

Table 3. Comparison of motion response varied from different sea levels (relative value).

\begin{tabular}{|c|c|c|c|c|c|c|c|c|}
\hline $\begin{array}{c}\text { Sea } \\
\text { Level }\end{array}$ & $\begin{array}{c}\text { Average } \\
\text { Wave Height }\end{array}$ & Angular Limit & $\boldsymbol{x}(\mathbf{m})$ & $\boldsymbol{y}(\mathbf{m})$ & $\boldsymbol{z}(\mathbf{m})$ & $\boldsymbol{\varphi}\left({ }^{\circ}\right)$ & $\boldsymbol{\theta}\left({ }^{\circ}\right)$ & $\boldsymbol{\psi}\left({ }^{\circ}\right)$ \\
\hline 2 & $0.5978 \mathrm{~m}$ & $1.222 \sim 3.225 \mathrm{rad} / \mathrm{s}$ & 0.888 & 0.641 & 0.041 & 0.111 & 0.375 & 0.018 \\
\hline 3 & $1.1440 \mathrm{~m}$ & $0.8836 \sim 2.331 \mathrm{rad} / \mathrm{s}$ & 2.221 & 0.646 & 0.191 & 0.575 & 0.459 & 0.176 \\
\hline 4 & $1.8410 \mathrm{~m}$ & $0.6966 \sim 1.838 \mathrm{rad} / \mathrm{s}$ & 3.199 & 0.789 & 0.333 & 1.274 & 0.734 & 0.351 \\
\hline 5 & $3.6120 \mathrm{~m}$ & $0.4973 \sim 1.312 \mathrm{rad} / \mathrm{s}$ & 5.876 & 1.238 & 0.520 & 8.701 & 0.796 & 1.181 \\
\hline
\end{tabular}

Learned from the above analysis, 6-DOF motion response maximum value will increase with the increase of sea level. Among that, the average wave height under level 2 is relatively low. Specifically, the level 4 and 5 sea condition are our key researching target in this project. The heaving $(0.333 \mathrm{~m})$, rolling $\left(1.274^{\circ}\right)$ and pitching $\left(0.734^{\circ}\right)$ under level 4 sea condition will offer reference data to develop AHC detection system. Moreover, it is easy to know that surging and rolling have relatively high response amplitude from the response curves because there is no restraint in this direction.

\section{SUMMARY}

This research has successfully accomplished the 6-DOF motion simulation of vessel waving in the ocean under various sea conditions, taking hoisting in the sea as the background and ANSYS AQWA software as the experimental platform. Firstly, the paper simplifies the vessel modeling process under the reasonable hypothesis. Then, the velocity trend function was researched combined with three dimensional potential theory. Next, the paper analyses and calculates the sea loads respectively based on step-by-step modelling methodology. Lastly, we verify the load design and insert the vessel model to resolve the static solution and time response with AQWA module in the ANSYS workbench platform. We can draw conclusions that the wave motion is non-linear transformation relationship. And the simulative data can guide the design of AHC detection system.

\section{References}

1. T. M. Williams, Heuristic Scheduling of Ship Replenishment at Sea, Journal of the Operational Research Society 43.1, 11-18(1992)

2. G. Thomas, Ship motions during replenishment at sea operations in head seas, International Journal of Maritime Engineering 152.4, A181-A196(2010)

3. X. J. Xu, X. Chen, J. Z. Shang, The Principle and Mathematical Modeling of a New Active Heave Compensation System, Journal of National Univ. of Defense Technology. 29(3), 118-122 (2007)

4. L. Yan, The research on key technology of vessel motion simulation based on sea conditions. Shanghai Jiao Tong University (2009)

5. P. A. Shi, Research on Wave Motion Compensation of Two Side-by-Side Positioned Ships, Jiao Tong University for Master Degree of Engineering (2013)

6. W. J. Lu, Study on system of missile sealifts with wave compensation for navy ships connected paralledly, Nanjing University of Science and Technology (2006)

7. C. Ebbesen, Analysis of Motions and Anchor Line Forces for Floating Production Units (Institute for Marin Teknikk, Norway, 2013) 
8. Telukunta, Srinivas, S. Mukherjee, The extended boundary node method for three-dimensional potential theory, Computers \& Structures, 17-18, 1503-1514 (2005)

9. M. O. Faltinsen, Sea loads on ships and offshore structures (Cambridge University Press, Cambridge, New York \& Melbourne, 1990)

10. China classification society: Specification for Marine Mobile Platforms (China classification society, Beijing, 2016)

11. G. Yan, J. Ou, Dynamic response analysis of TLP based on AQWA, Journal of Southeast University, 47(S1), S130-S137 (2009) 